\title{
Docetaxel-loaded solid lipid nanoparticles as a basis for a targeted and dose-sparing personalized breast cancer treatment strategy
}

This article was published in the following Dove Press journal:

International Journal of Nanomedicine

25 March 2015

Number of times this article has been viewed

\author{
Natalia $\vee$ Danilova ${ }^{1,2}$ \\ Zhomart R Kalzhanov ${ }^{3}$ \\ Nina A Nefedova ${ }^{2}$ \\ Pavel G Mal'kov ${ }^{2}$ \\ loannis $\mathrm{P}$ Kosmas ${ }^{1,4}$ \\ Marina $Y$ Eliseeva ${ }^{1,5}$ \\ Ospan A Mynbaev1,5,6 \\ 'International Translational \\ Medicine and Biomodeling Research \\ Team, MIPT Center for Human \\ Physiology, Laboratory of Cellular \\ and Molecular Technologies, \\ Moscow Institute of Physics \\ and Technology, State University, \\ ${ }^{2}$ Department of Physiology and Basic \\ Pathology, Faculty of Fundamental \\ Medicine, Lomonosov Moscow \\ State University, Moscow, Russia; \\ ${ }^{3}$ Department of Human Metabolism, \\ Academic Unit of Reproductive \\ and Developmental Medicine, Sheffield \\ University, Sheffield, UK; ${ }^{4}$ Department \\ of Obstetrics and Gynecology, \\ loannina State General Hospital \\ G Chatzikosta, loannina, Greece; \\ ${ }^{5}$ Department of Obstetrics, \\ Gynecology and Reproductive \\ Medicine, Peoples' Friendship \\ University of Russia, 'Laboratory of \\ Immunology, Moscow State University \\ of Medicine and Dentistry named \\ after Al Evdokimov, Moscow, Russia
}

Correspondence: Ospan A Mynbaev Moscow Institute of Physics and Technology, State University, Dolgoprudny, 9 Instituskii Lane, Dolgoprudny, Moscow 141700, Russia Email ospanmynbaev@hotmail.com

\section{Dear editor}

The long-term survival rate of patients with breast cancer was improved by the application of systemic adjuvant chemotherapy, ${ }^{1}$ although the primary breast cancer treatment strategy consists of mastectomy with lymphadenectomy and radiotherapy followed by breast reconstruction..$^{2-5}$ Unfortunately, most adjuvant chemotherapeutic agents trigger major side effects. ${ }^{1,6}$ Therefore, we have read with great interest an article in the International Journal of Nanomedicine on the design of docetaxel-loaded solid lipid nanoparticles (DSNs) aimed at reducing the systemic toxicity of standardized docetaxel treatment. ${ }^{7}$

Our congratulation to the authors ${ }^{7}$ for their clear demonstration of the reduced cytotoxicity of DSNs and significantly decreased myelosuppressive toxicity by recovering the proliferation and differentiation of bone marrow progenitor cells, while triggering more apoptosis in MCF-7 cells at a low dose compared with the commercial formula of docetaxel by an arrested cell cycle progression in the G2/M stage.

The acute necessity for such state-of-the-art studies is linked to a high worldwide incidence of breast cancer; in the World Health Organization Fact sheet, its increased metastatic potency is listed as one of the most common causes of cancer death. ${ }^{8}$

The incidence of breast cancer is high in Western European countries, ie, about 89.7 per 100,000 women. ${ }^{8}$ The same high incidence applies to other developed countries. For our part, we have analyzed the statistical data concerning breast cancer in the Russian Federation. ${ }^{9}$

According to the statistical report by the Federal Research Institute for Health Organization and Informatics of the Ministry of Health of the Russian Federation between 2003 and 2012 (Table 1), the 10-year breast cancer incidence rates average 68.99 per 100,000 women (an average of 52,647 women annually), of which $95.1 \%$ cases were histologically verified. The average 5-year survival rate was $56.2 \%$ among women with breast cancer followed up in state and municipal cancer institutions. The average annual mortality of patients with verified breast cancer was $10.0 \%$ among individuals who were followed up in cancer institutes. Subsequently, between 2003 and 2012, about 25,697 women per year died of breast cancer in the Russian Federation.

Our investigation, as proved by time series analysis (JMP7 software), revealed that the incidence of breast cancer had been rising continually, with increasing trends from 2003 to 2012 while at the same time the number of cancer deaths has been steadily decreasing (Table 1). Overall, the same trends exist for all cancer patients, in the same time. 


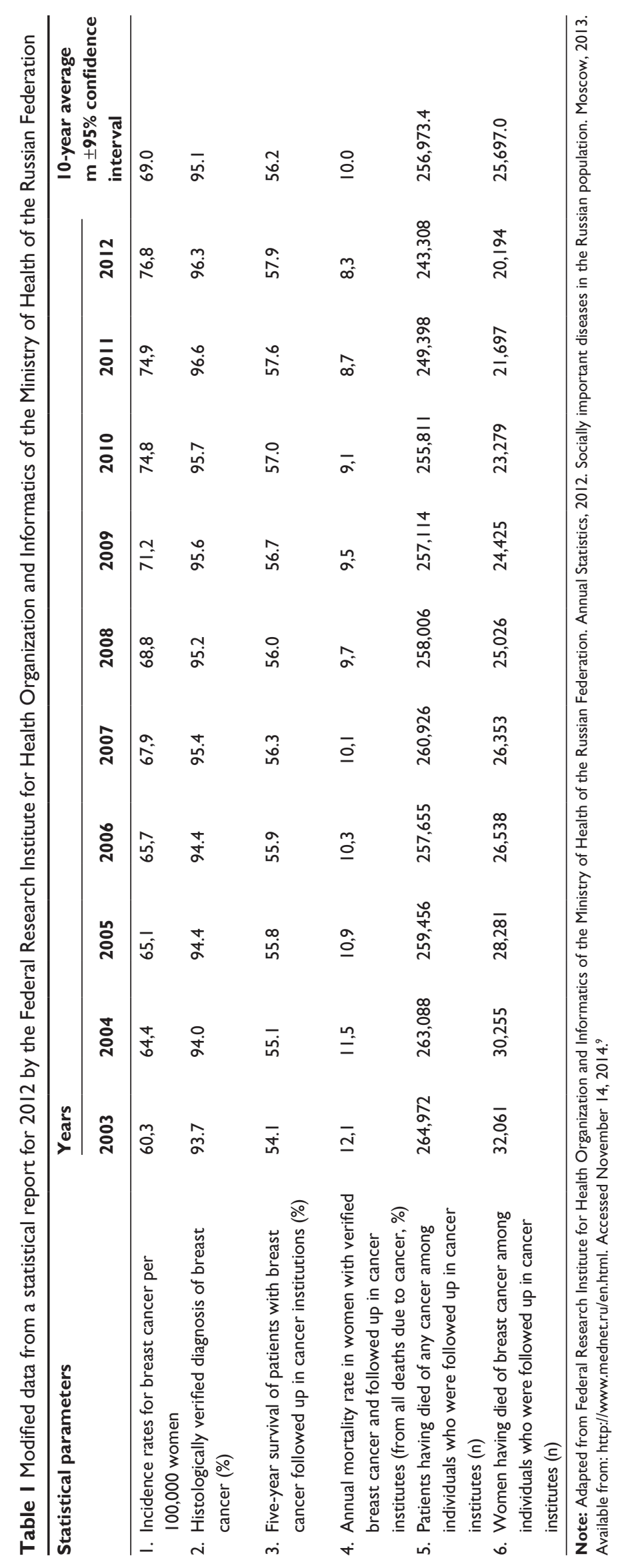


This phenomenon can be explained first by improvements in the Russian health care system. Government programs were set up applying new diagnostic technologies for early breast cancer screening, and preventive medical strategies were encouraged. Second, the rise in incidence of breast cancer might also be associated with gradual lifestyle changes. Many mothers in Russia decline breastfeeding and, in addition, worldwide environmental changes are reflected in an increased incidence of breast cancer, including in countries with a low prevalence of the disease.

This brief analysis demonstrates that our modern community calls for new therapeutic approaches in the treatment of breast cancer. We believe that further studies could show the application of DSNs to be a basic compound for a targeted and dose-sparing personalized breast cancer treatment strategy.

\section{Acknowledgment}

This work was supported by the Russian Science Foundation (grant 14-31-00024). All authors are members of the International Translational Medicine and Biomodeling Research Team (http://mathbiomed.crec.mipt.ru).

\section{Author contributions}

All authors contributed to the discussion regarding the original study by Yuan et al, ${ }^{7}$ and revising the final manuscript, and agree to be accountable for all aspects of the work.

\section{Disclosure}

The authors report no conflicts of interest in this work.

\section{References}

1. Rampurwala MM, Rocque GB, Burkard ME. Update on adjuvant chemotherapy for early breast cancer. Breast Cancer (Auckl). 2014; 8:125-133.

2. Kurian AW, Lichtensztajn DY, Keegan TH, Nelson DO, Clarke CA, Gomez SL. Use of and mortality after bilateral mastectomy compared with other surgical treatments for breast cancer in California, 1998-2011. JAMA. 2014;312:902-914.

3. Burki TK. Increases in bilateral mastectomy for breast cancer. Lancet Oncol. 2014;15:e480

4. Halsted CP, Benson JR, Jatoi I. A historical account of breast cancer surgery: beware of local recurrence but be not radical. Future Oncol. 2014;10:1649-1657.

5. Berbers J, van Baardwijk A, Houben R, et al. Reconstruction: before or after postmastectomy radiotherapy? A systematic review of the literature Eur J Cancer. 2014;50:2752-2762.

6. Hugenholtz-Wamsteker W1, Robbeson C, Nijs J, Hoelen W, Meeus M. The effect of docetaxel on developing oedema in patients with breast cancer: a systematic review. Eur J Cancer Care (Engl). October 27, 2014. [Epub ahead of print].

7. Yuan Q, Han J, Cong W. Docetaxel-loaded solid lipid nanoparticles suppress breast cancer cells growth with reduced myelosuppression toxicity. Int J Nanomedicine. 2014;9:4829-4846.

8. World Health Organization. Cancer Fact sheet 297. Key facts. Available from: http://www.who.int/mediacentre/factsheets/fs297/en/. Accessed November 14, 2012.

9. Federal Research Institute for Health Organization and Informatics of the Ministry of Health of the Russian Federation. Annual Statistics, 2012 Socially important diseases in the Russian population. Moscow, 2013. Available from: http://www.mednet.ru/en.html. Accessed November 14, 2014. 


\section{Authors' reply \\ Qing Yuan' \\ Jing $\operatorname{Han}^{1,2}$ \\ Wenshu Cong' \\ Ying $\mathrm{Ge}^{3}$ \\ Dandan $\mathrm{Ma}^{1,3,4}$ \\ Zhaoxia Dai ${ }^{3,4}$ \\ Yaping $\mathrm{Li}^{5}$ \\ Xiaolin $\mathrm{Bi}^{1,3,4}$ \\ 'CAS Key Laboratory for Biological Effects of Nanomaterials and Nanosafety, Institute of High Energy Physics, Chinese Academy of Sciences, Beijing, People's Republic of China; ${ }^{2}$ School of Life Sciences, Anhui University, Hefei, People's Republic of China; ${ }^{3}$ Cancer Center, Institute of Cancer Stem Cell, ${ }^{4}$ Graduate School, Dalian Medical University, Dalian, People's Republic of China; \\ ${ }^{5}$ Shanghai Institute of Materia Medica, Chinese Academy of \\ Sciences, Shanghai, People's Republic of China}

Correspondence: Xiaolin $\mathrm{Bi}$

CAS Key Laboratory for Biological Effects of Nanomaterials and

Nanosafety, Institute of High Energy Physics, Chinese Academy

of Sciences, Beijing 100049, People's Republic of China

Tel +861088236709

Fax +86 I0 88236456

Email bixl@ihep.ac.cn

\section{Dear editor}

As we all know, breast cancer is the most significant cause of mortality among females both in developing and developed countries recent years. ${ }^{1,2}$ In 2008, the percentage of breast cancer was $23 \%$ in total new cancer cases and death by breast cancer was $14 \%$ in total cancer death. ${ }^{2}$ We now know that the breast cancer incidence is high in the Russian Federation from the analysis by Danilova et al. Based on their data, Danilova et al found that incidence of breast cancer was increased yearly while the mortality had been reduced continually in Russian Federation from 2003 to 2012.

The incidence rates and mortality rates of breast cancer between developing and developed countries showed some differences. In 2008, about $50 \%$ of the breast cancer cases occurred in developing countries and the percentage of cancer deaths is $60 \%{ }^{2}$ While developed countries have the relative high incidence rates and the death rates have been decreasing continually. In contrast, incidence and mortality rates have been rising in many African and Asian countries such as Uganda and India. ${ }^{1}$ These data indicated that breast cancer patients especially those in developing countries need more efficient and affordable therapy.

Systemic adjuvant chemotherapy can improve outcomes after surgery for breast cancer patients. ${ }^{3}$ Unfortunately, most adjuvant chemotherapeutic agents, including docetaxel-one of the most effective adjuvant therapy drugs, cause serious side effect..$^{3-6}$ Lots of efforts has been put into reducing side effects and enhancing antitumor activity, such as using nanotechnology to improve the formulations. ${ }^{7-14}$ Lipids are safe materials with good biocompatibility for drug formulations, some lipidbased formulations of anticancer drugs have been approved by the US Food and Drug Administration, such as Doxorubicin liposomal (New Drug Application (NDA) number 050718). To date, lipid-based nanoparticles have been proved to be one of the most promising drug-delivery candidates. ${ }^{15,16}$

We prepared the docetaxel-loaded solid lipid nanoparticles (DSNs) which can significantly reduce the side-effect of docetaxel. ${ }^{14,17}$ Moreover, DSNs have lots of advantages compared with other nanoformulations, such as component safety, easier preparation, better stability, and controlled release etc that will promote its clinical application..$^{14,18}$ These features make DSNs a potential economical adjuvant chemotherapeutic drug for breast cancer therapy with higher efficacy, especially affordable for patients in developing countries.

We appreciate Danilova et al proposed DSNs as a basic compound for a targeted and dose-sparing personalized breast cancer treatment strategy. There are a lot of problems that need to be overcome, such as large-scale production, targeting conjugation and on-demand release before DSNs' clinical use. We believe with the development of nanotechnology and pharmaceutics, the more effective docetaxel formulations based on DSNs will be developed and applied in the future.

\section{Acknowledgments}

This work was supported by grants from National Basic Research Program of China (973 Program grant numbers 2010CB934004 and 2010CB934003), National Natural Science Foundation of China (grant number 31271480), Program of Changjiang Scholar and Innovative Research Team in University (IRT13049) and CAS Knowledge Innovation Program to Xiaolin Bi.

\section{Disclosure}

The author reports no conflicts of interest in this communication.

\section{References}

1. Jemal A, Bray F, Center MM, Ferlay J, Ward E, Forman D. Global cancer statistics. CA: a cancer journal for clinicians. 2011;61(2):69-90.

2. Ferlay J, Shin HR, Bray F, Forman D, Mathers C, Parkin DM. Estimates of worldwide burden of cancer in 2008: GLOBOCAN 2008. Int J Cancer. 2010;127(12):2893-2917.

3. Rampurwala MM, Rocque GB, Burkard ME. Update on adjuvant chemotherapy for early breast cancer. Breast cancer (Auckl). 2014;8: $125-133$. 
4. Saloustros E, Mavroudis D, Georgoulias V. Paclitaxel and docetaxel in the treatment of breast cancer. Expert Opin Pharmacother. 2008;9(15):2603-2616.

5. Crown J, O'Leary M, Ooi WS. Docetaxel and paclitaxel in the treatment of breast cancer: a review of clinical experience. Oncologist. 2004;9 Suppl 2:24-32.

6. Baker J, Ajani J, Scotte F, et al. Docetaxel-related side effects and their management. Eur J Oncol Nurs. 2009;13(1):49-59.

7. Hwang HY, Kim IS, Kwon IC, Kim YH. Tumor targetability and antitumor effect of docetaxel-loaded hydrophobically modified glycol chitosan nanoparticles. J Control Release. 2008;128(1):23-31.

8. Esmaeili F, Dinarvand R, Ghahremani MH, Ostad SN, Esmaily H, Atyabi F. Cellular cytotoxicity and in-vivo biodistribution of docetaxel poly(lactide-co-glycolide) nanoparticles. Anticancer Drugs. 2010;21(1):43-52.

9. Yanasarn N, Sloat BR, Cui Z. Nanoparticles engineered from lecithinin-water emulsions as a potential delivery system for docetaxel. Int J Pharm. 2009;379(1):174-180.

10. Immordino ML, Brusa P, Arpicco S, Stella B, Dosio F, Cattel L. Preparation, characterization, cytotoxicity and pharmacokinetics of liposomes containing docetaxel. J Control Release. 2003;91(3):417-429.

11. Elsabahy M, Perron ME, Bertrand N, Yu GE, Leroux JC. Solubilization of docetaxel in poly(ethylene oxide)-block-poly(butylene/styrene oxide) micelles. Biomacromolecules. 2007;8(7):2250-2257.
12. Liu J, Zahedi P, Zeng F, Allen C. Nano-sized assemblies of a PEGdocetaxel conjugate as a formulation strategy for docetaxel. JPharm Sci. 2008;97(8):3274-3290.

13. Zheng D, Li D, Lu X, Feng Z. Enhanced antitumor efficiency of docetaxel-loaded nanoparticles in a human ovarian xenograft model with lower systemic toxicities by intratumoral delivery. Oncol Rep. 2010;23(3):717-724.

14. Gao Y, Yang R, Zhang Z, Chen L, Sun Z, Li Y. Solid lipid nanoparticles reduce systemic toxicity of docetaxel: performance and mechanism in animal. Nanotoxicology. 2011;5(4):636-649.

15. Puri A, Loomis K, Smith B, et al. Lipid-based nanoparticles as pharmaceutical drug carriers: from concepts to clinic. Crit Rev Ther Drug Carrier Syst. 2009;26(6):523-580.

16. Porter CJ, Trevaskis NL, Charman WN. Lipids and lipid-based formulations: optimizing the oral delivery of lipophilic drugs. Nat Rev Drug Discov. 2007;6(3):231-248.

17. Yuan Q, Han J, Cong W, et al. Docetaxel-loaded solid lipid nanoparticles suppress breast cancer cells growth with reduced myelosuppression toxicity. Int J Nanomedicine. 2014;9:4829-4846.

18. Zhang P, Chen L, Zhang Z, Lin L, Li Y. Pharmacokinetics in rats and efficacy in murine ovarian cancer model for solid lipid nanoparticles loading docetaxel. J Nanosci Nanotechnol. 2010;10(11):7541-7544.
International Journal of Nanomedicine

\section{Publish your work in this journal}

The International Journal of Nanomedicine is an international, peerreviewed journal focusing on the application of nanotechnology in diagnostics, therapeutics, and drug delivery systems throughout the biomedical field. This journal is indexed on PubMed Central, MedLine, CAS, SciSearch $®$, Current Contents $\AA /$ Clinical Medicine,

\section{Dovepress}

Journal Citation Reports/Science Edition, EMBase, Scopus and the Elsevier Bibliographic databases. The manuscript management system is completely online and includes a very quick and fair peer-review system, which is all easy to use. Visit http://www.dovepress.com/ testimonials.php to read real quotes from published authors. 